\title{
Statement on the Covid-19 Pandemic and Economic, Social and Cultural Rights
}

\author{
Committee on Economic, Social and Cultural Rights
}

\section{Introduction*}

1. The Covid-19 pandemic is threatening to overwhelm public health care systems, and is having devastating impacts across the world on all spheres of life - the economy, social security, education, and food production. Tens of thousands of lives have already been lost, including those of doctors and nurses providing frontline medical treatment. Jobs have been lost and livelihoods imperilled due to restrictions to curb the transmission of the virus such as 'lockdowns'. Schools are closed in many affected countries, and people cannot gather for significant cultural and community events such as religious services, weddings or funerals. At the commencement of this statement, the Committee extends its sympathy to all victims of the pandemic and their families as well as the broader communities of which they are part.

2. The pandemic has deep negative impacts on the enjoyment of economic, social and cultural rights ('ESCRs'), especially the right to health of the most vulnerable groups. As elaborated below, States are under an obligation to take measures to prevent, or at least to mitigate, these impacts. However, if States do not act with within a human rights framework, a clear risk exists that the measures taken might violate ESCRs and increase the suffering of the most marginalized groups. No one should be left behind in taking the measures necessary to combat this pandemic. ${ }^{1}$ These circumstances have led the Committee to issue this statement to highlight the most important impacts of this pandemic on ESCRs and to make some recommendations to States to combat the COVID-19 pandemic in a manner consistent with their obligations under the Covenant.

* UN Doc E/C.12/2020, adopted by the Committee on 6 April 2020.

1 See UN Committee on Economic, Social and Cultural Rights Statement, "The Pledge to Leave No One Behind: The International Covenant on Economic, Social and Cultural Rights and the 2030 Agenda for Sustainable Development” UN Doc. E/C.12/2019/1 (5 April 2019). 


\section{Impacts of the Pandemic on Economic, Social and Cultural Rights}

3. The COVID-19 pandemic vividly illustrates the importance of the indivisibility and interdependence of all human rights. This pandemic is essentially a global health threat. However, it has multiple implications for the enjoyment of civil and political rights because some of the measures taken by States to combat it impose severe restrictions on the freedom of movement and other rights. Thus, it is essential that the measures adopted by States to combat this pandemic are reasonable and proportionate to ensure protection of all human rights.

4. Health care systems and social programmes have been weakened by decades of underinvestment in public health services and other social programmes, accelerated by the global financial crisis of $2007-2008 .^{2}$ Consequently, they are ill equipped to respond effectively and expeditiously to cope with the intensity of the current pandemic.

5. Disadvantaged and marginalised groups are severely affected by the current crisis. The elderly, those with pre-existing health conditions and compromised immune systems are particularly vulnerable to serious health consequences if infected by the coronavirus. Other groups are at greater risk of contagion such those in residential care facilities or communal living arrangements; prisoners and persons in detention facilities; and residents of informal settlements or other areas lacking adequate access to water, soap or sanitizer. Certain categories of workers such as delivery workers, garbage collection workers, manual labourers and farmworkers are exposed to heightened risks of being infected, as the nature of their work does not allow them to take advantage of dispensations to work from home using digital technology. Many health care workers, who are performing heroic work in the frontlines of responding to the pandemic, are being infected due to inadequacies or shortages of personal protective equipment and clothing. A number of groups are severely disadvantaged by the economic consequences of measures adopted in a number of countries to contain the spread of coronavirus. These include precarious workers in the 'gig-economy' or informal sector ${ }^{3}$ along with other groups of workers who face retrenchments or loss of wages

2 See Letter to State Parties by Chairperson of the UN Committee on Economic, Social and Cultural Rights, 16 March 2020; UN Committee on Economic, Social and Cultural Rights Statement, "Public Debt, Austerity Measures and the International Covenant on Economic, Social and Cultural Rights" UN doc. E/C.12/2016/1 (24 June 2016).

3 See the Committee's general comment No. 18; general comment No. 19 and general comment No. 23 . 
and social benefits, including domestic workers in many countries. Informal traders and a number of small businesses can no longer ply their trade or conduct business resulting in profound economic insecurity for themselves and their dependants.

6. Inadequate public goods and social programmes also deepen global income and wealth inequalities. Those living in poverty cannot afford to purchase the aforementioned goods and services in the private market, and they bear the disproportionate burden of the economic consequences of quarantines, 'lock downs', and the adverse national and international economic situation.

7. In countries where schools, technical colleges and higher educational institutions are closed, efforts are being made to continue teaching and learning online. These are important measures to mitigate the impact of these closures on the right to education. However, they also carry the risk of deepening educational inequalities between rich and poor learners due to unequal access to affordable internet services and equipment such as computers, smart phones and tablets.

8. The Covid-19 pandemic also threatens to deepen gender inequalities as the burden of caring for children at home and sick or elderly family members falls disproportionately on women given the still deeply embedded gender stereotypes and roles in many societies. In circumstances where families are in lock down or quarantine, women may be additionally vulnerable to domestic violence, and have limited recourse in these circumstances.

9. Indigenous peoples, refugees and asylum seekers, and those living in conflict-affected countries or regions are particularly vulnerable during this pandemic. Many lack adequate access to water, soap or sanitizer, Covid-19 testing facilities, health care services and information. These populations frequently suffer higher rates of chronic illnesses and underlying health conditions that place them at greater risk of developing severe health complications from Covid-19.

\section{Recommendations}

10. To ensure that Covenant rights and obligations are protected and fulfilled during this crisis, States should take a range of urgent measures. In particular, responses to the pandemic should be based on the "best available" scientific evidence to protect public health. ${ }^{4}$

4 See the Committee's general comment No. 25 on science. 
11. Where the measures adopted limit Covenant rights, they should comply with the conditions set out in article 4 of the Covenant. In essence, such measures must be necessary to combat the public health crisis posed by Covid-19, and be reasonable and proportionate. Emergency measures and powers adopted by States Parties to deal with the pandemic should not be abused, and should be lifted as soon as they are no longer necessary for protecting public health.

12. In responding to the pandemic, the inherent dignity of all people ${ }^{5}$ must be respected and protected, and minimum core obligations imposed by the Covenant should be prioritised. ${ }^{6}$ In this difficult context, access to justice and to effective legal remedies is not a luxury but an essential element to protect the ESCRs, especially of the most vulnerable and marginalized groups. Thus, for example, it is essential that law enforcement officials respond to cases of domestic violence, that domestic violence hotlines are operational, and that effective access to justice and legal remedies are accessible to women and children who are subject to domestic violence.

13. It is essential that States adopt appropriate regulatory measures to ensure that health care resources in both the public and private sector are mobilised and shared amongst the whole population to ensure a comprehensive, co-ordinated health care response to the crisis. ${ }^{7}$ As the front-line responders to this crisis, all health care workers must be provided proper protective clothing and equipment against contagion. It is also essential that they are consulted by decision-makers, and that due regard is paid to their advice. Health workers play a critical role in providing earlywarning signals of the spread of diseases such as Covid-19, and in recommending effective measures of prevention and treatment.

14. State parties are under an obligation to devote their maximum available resources for the full realization of all ESCRs, including the right to health. As this pandemic and the measures taken to combat it have had a disproportionate negative impact on the most marginalized groups, Sates must make all efforts to mobilize the necessary resources to combat CoviD-19 in the most equitable manner, in order to avoid imposing further economic burden on these marginalized groups. Allocation of resources should prioritize the special needs of these groups.

5 See Preamble to the International Covenant on Economic, Social and Cultural Rights.

6 See the Committee's general comment No. 3, paras 10 and 11.

7 See the Committee's general comment No.14 on right to the highest attainable standard of health. 
15. All States Parties should, as a matter of urgency, adopt special, targeted measures, including through international cooperation, to protect and mitigate the impact of the pandemic on vulnerable groups such as the elderly, persons with disabilities, refugees, and conflict-affected populations, as well as communities and groups subject to structural discrimination and disadvantage. Such measures include, amongst others, the provision of water, soap and sanitizer to communities who lack such access; targeted programmes to protect the jobs, wages and benefits of all of workers, including of undocumented migrant workers; imposing a moratorium on evictions or mortgage bond foreclosures against people's homes during the pandemic; providing social relief and income-support programmes to ensure food and income security to all those in need; taking specially tailored measures to protect the health and livelihoods of vulnerable minority groups such as the Roma, as well as of indigenous peoples; and ensuring affordable and equitable access to internet services by all for educational purposes.

16. All workers should be protected from the risks of contagion at work, and States should adopt appropriate regulatory measures to ensure that employers minimise the risks of contagion according to best practice public health standards. Until such measures are adopted, workers cannot be obliged to work and should be protected from disciplinary or other penalties for refusing to work without adequate protection. In addition, States should take immediate measures to protect the jobs, pensions and other social benefits of workers during the pandemic, and to mitigate its economic impacts through, for example, subsidising wages, providing tax relief, and establishing supplementary social security and income protection programs. ${ }^{8}$

17. Regulatory measures should also be adopted to prevent profiteering on foodstuffs and hygiene products as well as essential medicines and supplies. Recommended measures include lifting all VAT on such supplies during the pandemic, and subsidising the costs of essential foodstuffs and hygiene products to ensure that they are affordable to the poor.

18. Accurate and accessible information about the pandemic is essential both to reduce the risk of transmission of the virus, and to protect the population against dangerous disinformation. Such information is also crucial in reducing the risk of stigmatizing, harmful conduct against vulnerable groups, including those infected by the coronavirus. Such

8 On the protection of workers' rights under the Covenant, see generally General Comments 18,19 and 23 . 
information should be provided on a regular basis, in an accessible format and in all local and indigenous languages. Measures should also be taken to expedite access to affordable internet services and vital technical equipment by all students, particularly those in poorer communities and regions, so that they can benefit equally from on-line learning programmes while schools and higher education institutions are closed due to the pandemic.

19. The Covid-19 pandemic is a global crisis, which highlights the crucial importance of international assistance and co-operation, a core principle enshrined in the Covenant. ${ }^{9}$ Such international assistance and cooperation includes the sharing of research, medical equipment and supplies, and best practices in combating the virus; co-ordinated action to reduce the economic and social impacts of the crisis; and joint endeavours by all states to ensure an effective, equitable economic recovery. The needs of vulnerable and disadvantaged groups as well as fragile countries, including least developed countries, and countries in conflict and post-conflict situations should be at the centre of such international endeavours.

20. State parties have extraterritorial obligations related to global efforts to combat COVID-19. In particular, developed States should avoid decisions, such as imposing limits on the export of medical equipment, resulting in obstructing access to vital equipment to the world's poorest victims of the pandemic. Moreover state parties shall make sure that unilateral border measures do not hinder the flow or necessary and essential goods, particular staple foods and health equipment. Any restriction based on the goal for securing national supply shall be proportionate and take into consideration the urgent needs of other countries.

21. States should also use their voting powers in international financial institutions to alleviate the financial burden of developing countries in the combat of the pandemic, with measures such as granting these countries different mechanisms of debt relief. States parties should also promote flexibilities or other adjustments in applicable intellectual property regimes to allow universal access to the benefits of scientific advancements relating to Covid-19 such as diagnostic, medicines and vaccines.

22. Unilateral sanctions of an economic and financial nature weaken health care systems and can undermine efforts to combat coronavirus, especially in the context of the procurement of medical equipment and supplies. Such sanctions should be lifted to enable affected countries to have

9 See, for example, articles 2(1), articles 11 and 15 of the International Covenant on Economic, Social and Cultural Rights. 
access to the resources they need to effectively combat the Covid-19 health pandemic. ${ }^{10}$

23. Pandemics are a crucial example of the need of scientific international cooperation to face transnational threats. Virus and other pathogens do not respect borders. If adequate measures are not taken, a local epidemic can very quickly become a pandemic with devastating consequences. wHo's role in this field is fundamental, and should be supported. Combating pandemics effectively requires stronger commitments from States to international cooperation as national solutions are insufficient. Enhanced international cooperation should increase the preparedness of States and of international organizations, especially the wHO, to respond to pandemics, for instance through sharing of scientific information of potential pathogens. It should also improve early warning mechanisms, based on timely and transparent information provided by States on emerging epidemics that have the potential of becoming pandemics. This would allow early interventions, based on the best scientific evidence, aimed at controlling these epidemics and preventing them from becoming a pandemic. If a pandemic development, sharing of the best scientific knowledge and its applications, especially in the medical field, becomes crucial to mitigate the impact of the disease, and to expedite the discovery of effective treatments and vaccines. Finally, after the pandemic, scientific research should be promoted to learn lessons and increase preparedness for possible pandemics in the future.

24. Covid-19 has highlighted the critical role of adequate investments in public health systems, comprehensive social protection programmes, decent work, housing, food, water and sanitations systems, and institutions to advance gender equality. Such investments are crucial in responding effectively to global health pandemics, and in counteracting multiple, intersecting forms of inequality, including deep inequalities of income and wealth both within and between countries. ${ }^{11}$

25. Finally, the Committee calls upon all States Parties to ensure that the extraordinary mobilisation of resources to deal with the Covid-19 pandemic provides the impetus for long-term resource mobilisation towards the full and equal enjoyment of the economic, social and cultural rights enshrined in the Covenant. In so doing, they will lay the foundation for

\footnotetext{
10 See the Committee's general comment No.8 on relationship between economic sanctions and respect for economic, social and cultural rights.

11 See A/RES/70/1, Transforming our world: the 2030 Agenda for Sustainable Development, Goal 10.
} 
achieving the ideal of the Universal Declaration of Human Rights of achieving a world of "free human beings enjoying freedom from fear and want". ${ }^{12}$ Mechanisms to facilitate national and international cooperation and solidarity, as well as substantial investments in the institutions and programmes necessary for the realisation of ESCRS will ensure that the world is better prepared for future pandemics and disasters. The Committee intends to continue to monitor the impact of the Covid-19 pandemic on ESCRs through the fulfilment of its various mandates under the Covenant. 12 This commitment is also recognised in the preamble to the International Covenant on
Economic, Social and Cultural Rights. 